\title{
Desafios da computação móvel e usabilidade em sala de aula
}

\author{
Viviane Gomes da Silva*, Ranniéry Mazzilly Silva de Souza **, Maria João Gomes*** \\ *Instituto Federal de Educação, Ciência e Tecnologia do Amazonas, **Universidade do Estado do Amazonas, \\ ***Universidade do Minho
}

\begin{abstract}
Resumo
Este artigo relata a experiência em sala de aula na Universidade do Minho - Braga - Portugal, na disciplina de Sistemas Móveis e Ubíquos no Mestrado em Engenharia de Sistemas. Realizou-se a avaliação heurística de usabilidade de Nielsen nas aplicações desenvolvidas para dispositivos móveis por grupos. A metodologia embasou-se na aplicação de 3 projetos de 7 alunos; bem como, aos 9 usuários externos a sala de aula; fundou-se ainda na observação direta por uma especialista. Validou-se com questionário de perguntas fechadas no intuito de confirmar os dados coletados. Ao final descreveu-se o grau de usabilidade das aplicações e sugestões.

Palavras chave: Sistema móveis e ubíquos, interface homem-computador, usabilidade, avaliação heurística.
\end{abstract}

\section{Introdução}

A partir da convergência das tecnologias de comunicação, rede de computadores, dos microprocessadores e dos dispositivos eletrônicos digitais foi criado o conceito de ubiquidade (Araujo, 2003), no qual dispositivos inteligentes, móveis ou não, sincronizam-se entre si para prover aos usuários acesso imediato e universal a novos serviços, de forma transparente, que visam auxiliar o desenvolvimento das tarefas recorrentes do dia a dia. O objetivo maior da computação ubíqua é tornar o uso dos computadores e seus dispositivos simples, intuitivo e comum, visando assim que pessoas não percebam sua presença, mesmo quando os utilizam, incorporadas em nossas vidas (Júnior, 2011).

Concomitante a inclusão dessas tecnologias digitais, emerge a área de Interface Homem Computador (IHC), que estuda e avalia recursos com propósito de melhorar a comunicação e a interface dos sistemas. IHC incide sobre a facilidade de uso e também sobre o estudo de novas técnicas de interação que auxiliem as atividades do usuário e disponibiliza o acesso eficiente (Afonso, Cota, \& Groppo, 2008).

Este artigo relata e analisa a qualidade das interfaces desenvolvidas no Mestrado em Engenharia de Sistemas na Universidade do Minho - Braga - Portugal. A turma desenvolveu em grupo uma aplicação para dispositivo móvel em ambiente Android, utilizando os parâmetros de usabilidade para facilitar o uso, a aprendizagem e incentivar o uso dos usuários.

Foi realizada a avaliação heurística de usabilidade das aplicações desenvolvidas pelos grupos de estudantes desenvolvedores, por um especialista em usabilidade e por três estudantes novatos que testaram a aplicação e responderam um questionário de satisfação. Este estudo permitiu conhecer o grau de facilidade de uso e se a aplicação é útil e desperta motivação para adotá-la em suas tarefas rotineiras.

\section{Computação Ubíqua e Móvel}

O termo computação ubíqua, foi criado a partir do conceito de Mark Weiser em 1988 e publicado em 1991, em seu artigo "The Computer for the 21st Century" (Weiser, 1991). Segundo Weiser, os seres humanos estariam cercados pela computação e tecnologias de redes em seu ambiente, além disso, os computadores forneceriam sistemas inteligentes que conectados entre si, a trocar informações independentes, tornando-se então onipresentes (Lyytinen \& Yoo, 2002).Trata-se de uma área emergente e as pessoas confundem-se nos novos termos, como: computação pervasiva, computação ubíqua, computação móvel e tantos outros. Contudo, existem diferenças conceituais entre eles (Lyytinen \& Yoo, 2002).

A computação móvel consiste em sistemas computacionais distribuídos em diferentes dispositivos que comunicam-se entre si através de uma rede de comunicação sem fio, o que permite a mobilidade desses aparelhos (Adelstein, Sandeep, Golden, \& Schwiebert, 2005).

O conceito de computação pervasiva, termo introduzido pela IBM no mercado em 1998 (Ark \& Selker, 1999) promete tornar a vida mais simples através de ambientes digitais ao adaptar e responder às necessidades humanas. Computação pervasiva pressupõe uma visão diferente (Saha \& Mukherjee, 2003), implica que o computador está embarcado ao ambiente de forma invisível para o usuário, com capacidade de obter informações acerca do ambiente circundante e utilizá-la para controlar, configurar e ajustar a aplicação no ambiente. Levando em consideração as definições anteriores, com intuito de diferenciação, computação ubíqua é a associação da computação móvel com a pervasiva. A figura 1 exemplifica a relação entre estes termos.

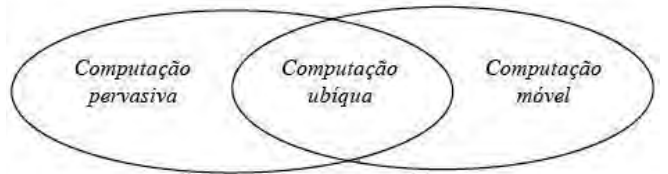

Figura 1. Relação entre computação ubíqua, pervasiva e móvel (Araujo, 2003). 


\section{Interface Homem-Computador}

O desenvolvimento e ampliação de sistemas ubíquos requer soluções de interfaces intuitivas, fáceis de utilizar e eficazes (Ark \& Selker, 1999). As melhores interfaces são aquelas intuitivas, cujo uso parece diretamente relacionado com sua função, portanto, para que aplicações sejam aprovadas pelos usuários é fundamental que estas sejam simples e fáceis de utilizar a partir da perspectiva e do contexto do usuário.

A medida que surgem desafios em tornar os sistemas mais próximos do mundo real, o interesse em IHC tem crescido na mesma proporção. IHC tem sido nos últimos anos uma das maiores áreas de pesquisa em ciência da computação, ergonomia, psicología, educação e disciplinas relacionadas, pois trata-se de uma área multidisciplinar (Helander, Landauer, \& Prabhu, 1997).

A usabilidade é uma qualidade que deve ser inerente ao sistema, que possibilita aos usuários utilizá-lo com satisfação e eficiência na realização das tarefas (Babo, 1996). Um sistema pode ser bem concebido em termos de funcionalidade, mas caso a usabilidade não seja adequada aquele contexto, o usuário rejeitá-lo-á.

Há 5 parâmetros que Nielsen (1995) considera como adequados para mensurar a usabilidade: fácil de aprender, o utilizador rapidamente consegue interagir com o sistema, aprendendo as opções de navegação e a funcionalidade dos botões; eficiente para usar, depois de ter aprendido como funciona, consegue localizar a informação que precisa; fácil de lembrar, mesmo para um utilizador que usa o sistema ocasionalmente, não tem necessidade de voltar a aprender como funciona, conseguindo lembrar-se; pouco sujeita a erros, os utilizadores não cometem muitos erros durante a utilização do sistema, ou se os cometem devem conseguir recuperar, não devendo ocorrer erros catastróficos; e agradável de usar, os usuários sentem-se satisfeitos com o sistema, gostam de interagir com ele.

Um desafio para os sistemas atuais é possuir os parâmetros referente a usabilidade, frente à quantidade crescente de acessos e uso das tecnologias móveis. A aplicação destes parâmetros é de fundamental importância e será o diferencial entre sistemas mais utilizados e sistemas que tornam-se obsoletos.

Conciliar a análise e aplicação da usabilidade com sistemas ubíquos, pode resultar em significativos efeitos no design e funcionalidade destes sistemas, por revelar aspectos de tarefas e atividades humanas em termos de argumentação e descoberta de caminhos efetivos que o provem e justifiquem, pois o desenvolvimento de aplicações em computador não são recomendáveis que ocorra por intuição ou tentativa e erro.

A usabilidade é medida através de um número de testes, entrevistas, questionários e pesquisa com usuários (os selecionados devem ser os mais representativos possíveis) que testem o sistema e realizem uma seleção de tarefas pré-determinada. Pode também ser mensurada através da execução de qualquer tarefa no ambiente da performance. Em ambos os casos, um ponto importante é saber que a usabilidade pode obter medidas satisfatórias para usuários e eficácia nas tarefas.

\section{Avaliação Heurística de Usabilidade}

Várias abordagens têm sido empregadas para avaliar a usabilidade de aplicações web no contexto móvel.

A Avaliação Heurística é um método baseado na verificação de uma pequena lista de regras (heurísticas) de forma econômica, fácil e rápida, descobrir grandes problemas potenciais da interface (Nielsen \& Molich, 1990; Nielsen, 1994). Esta forma de avaliação é a mais eficiente na medição de usabilidade, dada a sua facilidade de entendimento e agilidade de aplicação (Desurvire, 1994; Nielsen, 1995;), que pode ser empregada no desenvolvimento e na fase final do projeto de aplicações móveis.

O procedimento de aplicação da Avaliação Heurística é realizada por inspetores (especialista) através de analise das interfaces, verificando a conformidade das mesmas de acordo com as dez heurísticas propostas por Nielsen (1994). Cada inspetor deve relatar os problemas encontrados, categorizá-los conforme as heurísticas e, por fim, determinar o grau de severidade do defeito. Depois de toda execução da inspeção, é realizada uma reunião de discriminação, onde é feito a separação dos problemas e falso-positivos. Está técnica de avaliação foi utilizada nos estudos de caso relatados a seguir.

\section{Aplicações em Dispositivos Móveis desenvolvidas em sala de aula}

Como o objetivo de utilizar tecnologias e conceitos de Computação Móvel e Ubíqua e aplicar esses conhecimentos de forma prática, foi definido como requisito avaliativo no Mestrado em Engenharia de Sistemas, na disciplina de Computação Móvel e Ubíqua, o desenvolvimento de um projeto que criasse uma aplicação em dispositivo móvel para ambiente Android, em que o grupo, utilizassem usuarios exteriores para testar a aplicação a fim de analisar sua usabilidade e aceitabilidade.

Os resultados deste estudo de caso com sistemas ubíquos e usabilidade, apresentam aspectos interessantes aos aprendizes, desde aprender a utilizar uma nova linguagem de programação para ambiente Android, desenvolvimento do plano de atividades e protótipo, até pensar em quais são as soluções que carecem no mercado de aplicativos para dispositivos móveis e solucionar problemas de usuários com determinado interesse comum. Para composição deste estudo de caso, a turma foi divida em três grupos de trabalho: dois grupos composto por dois alunos e um grupo composto por três alunos. O primeiro Estudo de Caso 1 - projeto "Até Já" que 3 alunos criaram para auxiliar usuários de sistemas móveis com interesses em comum. O Estudo de Caso $2-$ "City Concerns", que auxilia cidadãos que tem interesse em comum na sua zona ou cidade e podem unir-se e comunicar-se para um objetivo e por último o Estudo de Caso 3 - Projeto "Quanto Tapp" que auxilia o usuário a encontrar eventos ou atualizar quais eventos irão ocorrer conforme sua preferencia. Conforme a descrição detalhada a seguir de cada do projeto: 


\section{Projeto “Até Já”}

O projeto "Até Já", foi desenvolvido por três alunos do Mestrado em Engenharia de Sistemas na disciplina de Sistemas Móveis e Ubíquos como requisito avaliativo prático da disciplina, assim como os demais grupos.

O projeto "Até Já" objetiva-se em permitir que um grupo arbitrário de pessoas compartilhe mutuamente informações num contexto concreto e de curta duração, sua localização a fỉm de facilitar sua localização. Ao contrário das aplicações correntes, o cenário de utilização não está relacionado com amigos, nem tão pouco com o encontrar pessoas próximas com interesses semelhantes. Os cenários pressupõem situações de sincronização ocasional como por exemplo: a entrega de uma pizza, ou um grupo de turistas que passeiam de forma autônoma no centro de uma cidade, ou alguém que quer enviar a um conjunto de convidados de um evento um convite para participarem a partir da proximidade do local onde se encontram.
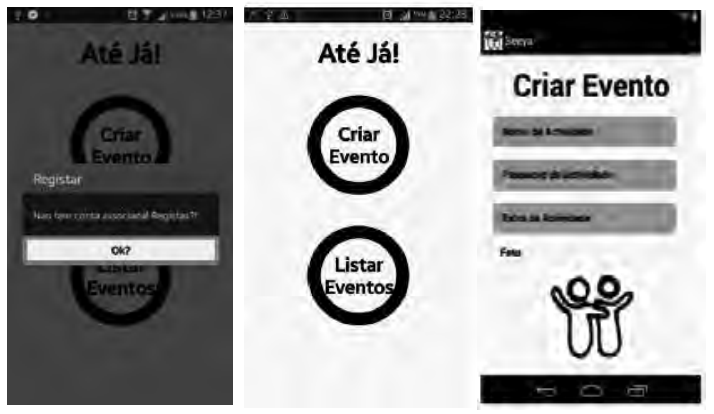

Figura 2. Interface da aplicação "Até Já"

Foi desenvolvido um protótipo da aplicação móvel em ambiente Android, em 3 smartphones e foram testadas por 6 usuários, sendo 3 membros do grupo e 3 estudantes de outros cursos da Universidade do Minho.

Ao final da realização do projeto e avaliação de novos usuários, o grupo relatou que foi um trabalho enriquecedor, tanto no nível acadêmico como para o desenvolvimento profissional. $\mathrm{O}$ acompanhamento integral por parte de cada membro do grupo representa uma mais valia, pois permite a compreensão no "comportamento" do utilizador na interação com a aplicação em todo o processo da avaliação. Através desta ação, é possível retirar algumas conclusões extras, de forma a melhorar a qualidade da aplicação. No final, todos os envolvidos na avaliação respondem a um inquérito de satisfação e avaliação, em que descreveram preferirem o modo de apresentação da localização por mapa, oposto as indicações textuais. Todos os usuários avaliados conseguiram chegar ao local combinado dentro do tempo estipulado conforme planejado, estes como pontos positivo. Por outro lado, como pontos a melhorar: reclamam da ausência de contato alternativo com o guia e os restantes de usuários diretamente através da aplicação (chat não foi implementado). Sugeriram alternativas para a recepção dos convites (facebook por ex.) e solicitaram ligação à Internet obrigatória.

Diante do exposto, os integrante do grupo concluíram que com os novos desafios ao nível da mobilidade, redução de custos e monitorização da informação, torna-se imperativa a atualização e adaptação dos sistemas de informação para maior agilidade no processo de tomada de decisão e eficácia na gestão do tempo de cada equipa. Portanto, a revolução dos dispositivos móveis não passa apenas por inovação a nível de hardware, mas também pelo nível da qualidade, disponibilidade e experiência na utilização das aplicações móveis e ainda relataram que gostariam de continuar a melhorar a aplicação como trabalho futuro.

\section{Projeto "City Concerns - CC"}

O principal objetivo do projeto "City Concerns, CC", é tornar o cidadão mais consciente e participativo do que o rodeia na sua comunidade. Com este projeto pretende-se fornecer uma ferramenta de suporte à comunicação e torná-la parte do quotidiano dos cidadãos, que seja significativa ao ponto de ajudar a melhorar a vida deste, ou no mínimo torná-la mais informada.

A solução apresentada abordada a falta de comunicação que existe entre os cidadãos da mesma comunidade, que residem na mesma área geográfica e tenham interesses comuns. Infelizmente, na maioria das vezes os cidadãos decidem ser ativos na sociedade quando existe um problema que o afeta diretamente, e geralmente é tarde para tratar decidir com o grupo afetado, mesmo quando há uma proposta ou possível solução sobre uma determinada área. Geralmente, a adesão é mínima e como consequência não conseguem uma forma para mostrar a solução viável ao grupo.

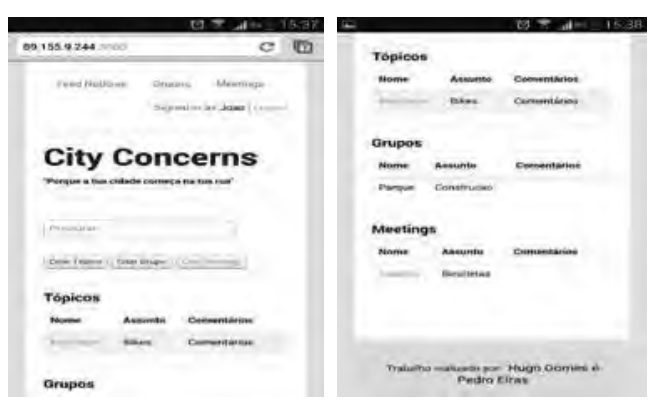

Figura 3. Protótipo da aplicação (tela "criar evento”)

O objetivo da aplicação é que funcionasse como um misto de rede social e um fórum. O projeto foi realizado com conhecimentos relativo a aplicações no âmbito da participação cívica do cidadão e partir deste estudo foi possível desenvolver as funcionalidades propostas para o teste com usuários. Foi elaborado uma base sólida sobre participação cívica entre comunidades permitindo que trabalhos futuros possam iniciar.

A respeito da avaliação de satisfação dos usuários entrevistado, foi sugerido por um dos inquiridos, ser proveitoso visualizar o funcionamento da aplicação com grupos, adicionando vários conjuntos de tópicos/assuntos, com o objetivo de comparar com uma rede social. No geral, o protótipo foi aprovado pelos usuários e correspondia de forma adequada e inteligente ao que foi proposto realizar.

Como trabalho futuro, o grupo pretende melhorar o protótipo, nos seguintes aspectos: transformar a aplicação web para web mobile, implementar o registo com vários níveis, implementar as notificações estilo pop-up, reformular base de dados, pesquisa sobre a 
melhor plataforma e estudo sobre o impacto de publicidade.

\section{Projeto “Quanto Tapp”}

Os objetivos principais do projeto "Quanto Tapp", primam pela necessidade de oferecer aos usuários informações em tempo real de acontecimentos subscritos, tais como:i) informar os resultados: tempo, localização, preço, fotos/vídeos, comentários e chat em tempo real de várias modalidades desportivas, de eventos culturais ou sociais; ii) pesquisar eventos que vão acontecer perto do local onde o usuário se encontra; iii) pesquisar eventos durante um intervalo de tempo; iv) garantir que seja fácil a criação de eventos; v) facilidades na temática da localização de eventos, ou seja, pretendemos que um utilizador encontre facilmente o evento que procura, ou até possibilitar a descoberta de um evento que lhe interesse; vi) Importação de eventos existentes na web.

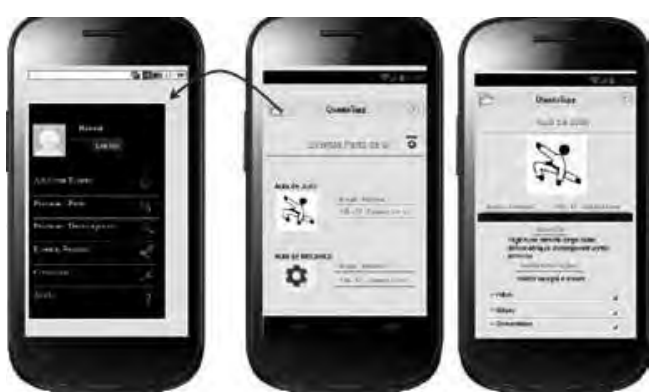

Figura 4. Protótipo da Aplicação Quanto Tapp - (tela "criar evento")

A avaliação do protótipo foi executada por 3 pessoas, que utilizaram a aplicação e contribuíram com sugestões e relataram pontos positivos e pontos a melhorar. Um dos itens que foram avaliados, foi o item Criação de Eventos, em que um dos usuários relatou que a criação de eventos é simples, no entanto, é demasiado simples e poderia ser complementada com mais funcionalidades, o segundo usuário descreveu que o design, é simplista, mas deveria ser mais bonito, como vantagem fácil de criar eventos, mas feio, outro usuário descreveu como a interface não é agradável, portanto, faltam campos para tornar a interface motivadora.

Outro item que foi avaliado, refere-se a Procura de eventos, em que os usuários relataram como: demasiado fácil procurar eventos que existem na zona; Aparecem diretamente na landing page da aplicação. Podia ser mais visível. Os eventos deviam ter imagens a ilustrar. Outro usuário declarou Gostar da homepage; consigo facilmente ver os eventos da zona; e é engraçado visualizar os eventos que vão acontecer; mas, um design mais apelativo era interessante, talvez a adição de imagens ajudasse. $\mathrm{O}$ último usuário entrevistado declarou a interface é simples e a informação acessível.

$\mathrm{O}$ item interação com eventos, foi avaliado pelos usuários que relataram como: apesar de estar apenas implementado os comentários, é interessante pensar numa interação com os eventos, carece de aprimoramento. Outro usuário relatou ter dificuldades em encontrar o botão de comentários, quando localizou-o descreveu os comentários e identificou que funcionaram bem. O último usuário descreveu que os comentários funcionam bem, mas ainda não é possível ter uma noção real da interação.

Como avaliação geral da aplicação os usuários relataram que a ideia é interessante, "ter a capacidade de encontrar os eventos que irão ocorrer numa zona próxima de onde me encontro é bom". Outro usuario declarou: não sei se perdia tempo a pesquisar eventos destas forma, tendo em conta o estado da aplicação, mas, reconheço que se o design for mais agradável é uma boa ideia. A aplicação seria mais utilizada se tivesse mais dados e categorias e necessita de um design melhor, talvez a inclusão de fotos e figuras.

\section{Análise dos resultados}

A análise dos resultados foi obtida por meio de um questionário de avaliação heurística de usabilidade aplicado junto a um perito na área da usabilidade e das tecnologias móveis e aos integrantes do grupo de desenvolvimento de cada aplicação, além de entrevistas de satisfação junto aos estudantes externos e/ou de outros cursos.

Referente a Visibilidade do Status do Sistema (em que avisa ao usuário sobre o que está acontecendo), foi detectado que há somente um problema "cosmético", isto é, que não precisa ser consertado caso não haja tempo disponível, as três aplicações mantém o usuário sempre atualizado do que está ocorrendo na aplicação.

Relativo ao item 2, (Compatibilidade do Sistema Com o Mundo Real/ em que o sistema precisa falar a linguagem do usuário e seguir convenções do mundo real) foi observado que talvez por se tratar de aplicações que ajudam o usuário em tarefas rotineiras, todas as três aplicações não apresentaram problemas pois fazem com que a informação aparece numa ordem natural e lógica.

No item 3 (Controle do Usuário e Liberdade / análise do que ocorre quando os usuários escolhem por engano funções do sistema e precisam sair do estado indesejado, sem ter que percorrer um extenso diálogo) as três aplicações apresentaram problemas "graves" devido a escassez de caixas de diálogos que oriente o usuário, quando acessa algo por engano. Neste sentido, todas as aplicações necessitam de melhoras nos atributos que informem ao usuário qual o caminho a seguir.

No item 4 (Consistência de Padrões / em que os usuários não precisem adivinhar que diferentes palavras, situações ou ações significam a mesma coisa) foi detectado problema "leve" devido a simplificação das ações das tarefas realizadas pelo usuário, não foi possível identificar um padrão para diferentes termos ou situações que significam a mesma coisa. $\mathrm{O}$ que torna necessário melhor ajuste na interface de todos aplicações.

Sobre o ítem 5 (Prevenção de Erros /em que o sistema deve evitar que o erro aconteça, informando ao usuário sobre as consequências de suas ações) foram detectadas em todas as aplicações problemas "graves" e de "alta prioridade" já que as aplicações não possuíam tratamento de segurança que evitasse a ocorrência de erro, informando aos usuários sobre as suas consequências.

Relativamente ao ítem 6 (Reconhecimento ao Invés de Relembrar / em que o sistema deve tornar objetos, ações 
e opções visíveis) as três aplicações apresentaram problema "leve" visto que faltava melhorar o design dos botões, opções e ações visíveis para o usuário, portanto necessária a inclusão de figuras para facilitar a memorização.

No item 7 (Flexibilidade e Eficiência de Uso / em que os usuário novatos se tornam peritos com o uso) foram consideradas nas três aplicações um problema "cosmético" pois neste quesito os usuários novatos relataram que após as primeiras explicações de utilização da aplicação, consideraram fácil o uso e aprendizagem.

No item 8 (Estética e Design Minimalista / em que os diálogos não devem conter informações irrelevantes ou raramente necessárias) foram identificados problema "grave", uma vez que as aplicações deveriam conter informações relevantes e necessárias e não o contrário, mas talvez devido o tempo limitado para o desenvolvimento do projeto, os estudantes não investiram em informações e opções para auxiliar os usuários.

No item 9 (Ajudar os Usuários a Reconhecer, Diagnosticar e Corrigir Erros / em que as mensagens de erro devem ser expressas em linguagem clara, sem códigos, indicando precisamente o problema e sugerindo soluções) foi identificado erro "grave e de alta prioridade" em todas as aplicações nos respectivos grupos de trabalho porque não foram desenvolvidas nas aplicações mensagens de erro que devem ser claras, indicando precisamente o problema para o usuário e sugerindo solução.

No último item 10 (Help e Documentação / em que é necessário prover ajuda e documentação fáceis de encontrar, focalizando na tarefa do usuário) foi considerado por todos avaliadores como um erro “catastrófico" ou seja, será imperativo consertá-lo, visto que não há documentação acessível para orientar o usuário.

\section{Conclusão}

Com a análise da avaliação heurística em aplicações para dispositivos móveis foi possível visualizar alguns dos desafios que sistemas ubíquos oferecem. A Interface Homem Computador (IHC) como o campo destinado a aproximação e facilitação entre o homem e o computador, a Tecnologia Educativa das Ciências da Educação - expressam conjuntamente que a interdisciplinaridade tornará mais curto o caminho para a formação de profissionais que busquem e desenvolvam com critério soluções as novas gerações de tecnologias. Porquanto, a velocidade com que surgem novos dispositivos no mercado não é a mesma com que pesquisas científicas são realizadas para desvelarem se de fato os usuários estão satisfeitos ou pelo menos tem conseguido manuseá-los em condições adequadas. É neste hiato, que este trabalho logrou desvelar fatores presentes na gênese de uma nova aplicação para dispositivos móveis.

\section{Referencias}

Adelstein, F., Sandeep, K. S., Golden, G. R. \& Schwiebert, L. (2005). Fundamentals of Mobileand Pervasive Computing. McGraw-Hill.

Afonso, A. P., Cota, M.P., \& Groppo, M. A. (2008). O efeito 'Dominó' na interacção humano-computador. Sistemas y Tecnologías de Información Vol 1. In 3. CISTI, Ourense, Espanha: Librotex.

Araujo, R. B. (2003). Computação ubíqua: princípios, tecnologias e desafios. In XXI Simpósio Brasileiro de Redes de Computadores. 8, 11-13.

Ark, W. \& S. Selker, T. (1999) "A look at human interaction with pervasive computers". IBM Systems Journal, Vol 38, No 4, 1999.

Babo, R. M. (1996). A avaliação da Usabilidade de um Sistema. Dissertação de Mestrado, Escola de Engenharia, Universidade do Minho, Braga, Portugal.

Desurvire, H. W. (1994). Faster, cheaper!! Are Usability Inspection Methods as Effective as Empirical Testing?. In: Nielsen, Jakob. Usability Inspection Methods Computer. New York, NY.

Helander, M. G., Landauer, T. K., \& Prabhu, P. V. (1997). Handbook Of Human-Computer Interaction. 2nd Ed. Elsevier, North-Holland, 1.582p.

Junior, P. J. (2011) Computação, Ubiquidade e Transparência. Revista de Estudos sobre as TIC, 79-94.

Lyytinen, K. \& Yoo, Y. (2002). Issues and Challenges in Ubiquitous Computing. Communications of the ACM, vol. 45 , no. 12 .

Nielsen, J. (1994) Usability inspection methods, Heuristic Evaluation. New York, NY.

Nielsen, J. (1995). Technology Transfer of Heuristic Evaluation and Usability Inspection.

Nielsen, J. \& Molich, R. (1990). Heuristic evaluation of user interfaces. Seattle, Washington, United States. http://www.acm.org/dl.

Saha, D. \& Mukherjee, A. (2003). Pervasive computing: a paradigm for the 21st century. In EEE Computer, 36(3), 25-31.

Weiser, M. (1991). The computer for the 21st century. Scientific American, 265(3), 94-104. 